\title{
Efficacia e sicurezza dell'analogo della triiodotiroinina (Triac) nei bambini e negli adulti con deficit di MCT8: un trial internazionale, a singolo braccio, open label di fase 2
}

\author{
Alessandro Brancatella ${ }^{1}$. Francesco Latrofa ${ }^{1}$
}

Accettato: 15 febbraio 2020 / Pubblicato online: 26 agosto 2020

(c) The Author(s) 2020

Commento a:

Effectiveness and safety of the tri-iodothyronine analogue Triac in children and adults with MCT8 deficiency: an international, single-arm, open-label, phase 2 trial.

S. Groeneweg, R.P. Peeters, C. Moran, A. Stoupa, F. Auriol, D. Tonduti, A. Dica, L. Paone, K. Rozenkova, J. Malikova, A. van der Walt, I.F. de Coo, A. McGowan, G. Lyons, F.K. Aarsen, D. Barca, I.M. van Beynum, M.M. van der Knoop, J. Jansen, M. Manshande, R.J. Lunsing, S. Nowak, C.A. den Uil, M.C. Zillikens, F.E. Visser, P. Vrijmoeth, M.C. de Wit, N.I. Wolf, A. Zandstra, G. Ambegaonkar, Y. Singh, Y.B. de Rijke, M. Medici, E.S. Bertini, S. Depoorter, J. Lebl, M. Cappa, L. De Meirleir, H. Krude, D. Craiu, F. Zibordi, I. Oliver Petit, M. Polak, K. Chatterjee, T.J. Visser, W.E. Visser.

Lancet Diabetes Endo (2019) 7(9):695-706

Il trasportatore monocarbossilato 8 (MCT8) svolge un ruolo chiave nella fisiologia della funzione tiroidea favorendo, da un lato, la secrezione degli ormoni tiroidei nel circolo ematico e, dall'altro, il loro ingresso nei vari tessuti. Le mutazioni inattivanti del gene che codifica per l'MCT8, situato sul cromosoma $\mathrm{X}$, determinano l'insorgenza di una rara patologia, la sindrome di Allan-Herndon-Dudley caratterizzata da un grave deficit nello sviluppo del sistema nervoso associato a elevati livelli di T3 circolante, bassi livelli di T4 e tireotossicosi periferica (tachicardia, ipertensione, ipermetabolismo, calo ponderale). Questo particolare fenotipo (ipotiroidismo

F. Latrofa

francesco.latrofa@unipi.it

1 Unità di Endocrinologia 1, Dipartimento di Medicina Clinica e Sperimentale, Università di Pisa, Pisa, Italia a livello del sistema nervoso centrale e tireotossicosi periferica) è dovuto alla differente regolazione del trasporto degli ormoni tiroidei nei vari tessuti. A livello del sistema nervoso centrale l'ingresso degli ormoni è mediato quasi esclusivamente dall'MCT8, mentre negli altri tessuti cooperano differenti trasportatori. Gli elevati livelli di T3 circolante sono probabilmente da imputare a complessi meccanismi che riguardano il mancato utilizzo dell'ormone a livello cerebrale e l'aumentata conversione periferica conseguente alla rimodulazione dell'attività delle deiodasi.

Questa estrema complessità nella patogenesi rende molto difficile qualsiasi terapia. In passato è stato proposto il trattamento con propiciltiuracile associato a dosi sovrafisiologiche di levotiroxina nel tentativo di ridurre la sintomatologia e la morbilità associata all'ipotiroidismo centrale e alla tireotossicosi periferica. I risultati sono stati tuttavia deludenti e talora gravati da eventi avversi gravi, in particolar modo l'epatotossicità da propiltiouracile in bambini già esposti a numerosi trattamenti potenzialmente epatotossici (es. anticonvulsivanti) per le comorbilità associate alla malattia. È stata valutata quindi la possibilità di utilizzare analoghi della T3 che siano in grado di entrare nelle cellule cerebrali deficitarie per MCT8 e abbiano una blanda azione sui tessuti periferici.

In questo trial clinico multicentrico di fase 2 una di queste molecole (Triac) è stata somministrata a 46 pazienti per un anno allo scopo di valutarne gli effetti sulla tiretossicosi periferica. Al termine del trattamento, tutti i pazienti avevano avuto una significativa riduzione dei livelli di FT3 e ben l' $85 \%$ dei soggetti presentavano valori normali. Il raggiungimento del target veniva ottenuto in media dopo due mesi di terapia. Si assisteva, inoltre, a una significativa riduzione sia dei livelli di T4 che di TSH. Infine, venivano migliorati numerosi outcome clinici quali il peso corporeo, la frequenza cardiaca e la pressione arteriosa. Il 
profilo di sicurezza del farmaco è risultato buono e reazioni avverse correlate al Triac sono state registrate solo in 6 pazienti (13\%).

In conclusione, il Triac sembra essere un farmaco efficace nei pazienti con sindrome di Allan-Herndon-Dudley, perché in grado di ridurre le conseguenze dell'ipertiroidismo periferico. Ulteriori studi saranno necessari per valutare l'efficacia nel lungo periodo del trattamento e i possibili benefici sulle funzioni neurologiche.

Funding Note Open access funding provided by Università di Pisa within the CRUI-CARE Agreement.

Nota della casa editrice Springer Nature rimane neutrale in riguardo alle rivendicazioni giurisdizionali nelle mappe pubblicate e nelle affiliazioni istituzionali.
Open Access This article is licensed under a Creative Commons Attribution 4.0 International License, which permits use, sharing, adaptation, distribution and reproduction in any medium or format, as long as you give appropriate credit to the original author(s) and the source, provide a link to the Creative Commons licence, and indicate if changes were made. The images or other third party material in this article are included in the article's Creative Commons licence, unless indicated otherwise in a credit line to the material. If material is not included in the article's Creative Commons licence and your intended use is not permitted by statutory regulation or exceeds the permitted use, you will need to obtain permission directly from the copyright holder. To view a copy of this licence, visit http://creativecommons.org/licenses/by/4.0/. 